\title{
Direct Effect of Septic Plasma in Human Cell Lines Viability
}

\author{
Grazia Maria Virzì ${ }^{a, b} \quad$ Chiara Borga ${ }^{a, b} \quad$ Chiara Pasqualin ${ }^{a, b}$ Silvia Pastoria, b \\ Alessandra Brocca ${ }^{a-c}$ Massimo de Cal ${ }^{a, b}$ Federico Nalesso $^{a, b, d}$ \\ Monica Zanella ${ }^{a, b}$ Alessandra Brendolan ${ }^{a, b}$ Claudio Ronco ${ }^{a, b}$ \\ ${ }^{a}$ Department of Nephrology, Dialysis and Transplant, San Bortolo Hospital, Vicenza, Italy; ${ }^{\text {IRRIV-International }}$ \\ Renal Research Institute Vicenza, Vicenza, Italy; ' Unit of Internal Medicine and Hepatology (UIMH), Department of \\ Medicine, University of Padova, Padova, Italy; ${ }^{\mathrm{d}}$ Department of Medicine, UOC di Nefrologia 2, Azienda Ospedaliera, \\ University of Padova, Padova, Italy
}

\section{Keywords}

Sepsis · Humoral mediators · Apoptosis · Intrinsic and extrinsic pathways

\footnotetext{
Abstract

Background: Sepsis is a life-threatening condition often associated with a high incidence of multiple organs injury. Several papers suggested the immune response by itself, with the production of humoral inflammatory mediators, is crucial in determining organ injury. However, little is known of how sepsis directly induces organ injury at the cellular levels. To assess this point, we set up an in vitro study to investigate the response of renal tubular cells (RTCs), monocytes (U937) and hepatocytes (HepG2) after 24 h-incubation with septic patients' plasma. Methods: We enrolled 26 septic patients ("test" group). We evaluated cell viability, apoptosis and necrosis by flow cytometer. Caspase-3,-8,-9 and cytochrome-c concentrations have been analyzed using the Human enzyme-linked immunosorbent assay kit. Results: We found
}

\section{KARGER}

(c) 2018 S. Karger AG, Basel

E-Mail karger@karger.com

www.karger.com/bpu that a decrease of cell viability in all cell lines tested was associated to the increase of apoptosis in RTCs and U937 ( $p<$ $0.0001)$ and increase of necrosis in HepG2 $(p<0.5)$. The increase of apoptosis in RTCs and U937 cells was confirmed by higher levels of caspase-3 $(p<0.0001)$. We showed that apoptosis in both RTCs and U937 was triggered by the activation of the intrinsic pathway, as caspase-9 and cytochrome-c levels significantly increased $(p<0.0001)$, while caspase-8 did not change. This assumption was strengthened by the significant correlation of caspase- 9 with both cytochrome-c ( $r=0.73$ for RTCs and $r=0.69$ for U937) and caspase-3 ( $r=0.69$ for RTCs and $r=0.63$ for U937). Conclusion: Humoral mediators in septic patients' plasma induce apoptosis. This fact suggests that apoptosis inhibitors should be investigated as future strategy to reduce sepsis-induced organ damages.

(c) 2018 S. Karger AG, Basel 


\section{Introduction}

Sepsis has been recently defined as a "life-threatening organ dysfunction due to a dysregulated host response to infection" [1], a definition that emphasises the potential lethality of this systemic inflammatory state. Despite the progress made in sepsis treatment, sepsis remains a major cause of mortality and morbidity [2], and its incidence in western countries seems to be increasing over years [3] also due to a large population of elderly patients [4]. About $45 \%$ of septic patients experience multi-organ injury and failure, a complication that is associated to worst outcome and long-term organ dysfunction [5, 6]. Among organs involved, sepsis is frequently associated with respiratory, renal, neurological, hepatic and cardiovascular systems dysfunction [7]. Although the macroscopic effects of sepsis are evident (organ injury-dysfunction-failure-shock), little is known about what the direct effects of sepsis at the cellular level are. The immune response by itself, with the release of inflammatory soluble cell-derived mediators (cytokines, reactive oxygen species, platelet-activating factor, arachidonic acid metabolites, nitric oxide and related compounds) and activation of the major plasma cascade systems (complement, coagulation, and fibrinolytic systems), is thought to play a pivotal role in determining sepsis shock [8]. Specifically, it has been proved that septic-patients' plasma can directly cause necrosis and apoptosis of tubular cells, podocytes and microcirculation $[9,10]$. In addition, there is evidence of a correlation between plasmatic pro- (such as IL-6 and IL-8) or anti-(such as IL-10) inflammatory cytokines levels and mortality [11], as well as an association between endotoxin activity and renal cell apoptosis in Cardiorenal Syndrome Type- 5 patients $[12,13]$. However, the possibility to use inflammatory mediators in the diagnosis of sepsis and predicting outcomes is still controversial [14]. Overall, an in-depth understanding of the pathogenetic mechanisms of sepsis-associated organ injury is required to develop a curative sepsis therapy. To this end, we performed an in vitro study, where we investigated the direct effect of incubating septic patients' plasma with 3 different human cell lines (renal tubular cells [RTCs], monocytes and hepatocytes).

\section{Material and Methods}

\section{Subjects}

We enrolled 26 septic patients ("test" group) from the Intensive Care Unit of San Bortolo Hospital of Vicenza and 20 healthy volunteers (control group) of the Immune transfusion Center from the San Bortolo hospital of Vicenza. Sepsis was defined according with the American College of Chest Physicians and Society of Critical Care Medicine system. For each patient, demographic and clinical information (such as previous medical history, pharmacological treatment, co-morbidity, etc.) obtained were recorded at the time of hospitalization. Routine hospitalization analyses that were performed, including hemodynamic measurement (systolic/ diastolic artery pressure), blood and urine tests (urea, creatinine, albumin, haemoglobin, white blood cells count) and the standard bio-humoral screening (i.e., Brain Natriuretic Peptide, BNP), were also obtained.

\section{Sample Collection}

Blood samples have been collected from patients on their first day of diagnosis of sepsis. For each patient, peripheral EDTAblood sample was centrifuged for $10 \mathrm{~min}$ at $1,600 \mathrm{~g}$, to obtain plasma that was immediately collected and stored at $-80^{\circ} \mathrm{C}$ until use.

\section{Cell Line}

We used 3 different immortalized human cell lines: specifically, a line of RTCs, monocyte precursors (U937) and hepatic cells (HepG2). RTCs and U937 cell lines were grown in RPMI 1640 medium (International PBI, Milan, Italy), supplemented with $10 \%$ of heat-inactivated Fetal Bovine Serum (Sigma Chemical Co., St. Louis, MO, USA), $2 \mathrm{mM}$ L-glutamine, $100 \mathrm{IU} / \mathrm{mL}$ penicillin and $100 \mu \mathrm{g} / \mathrm{mL}$ streptomycin (Sigma Chemical Co., St. Louis, MO, USA). HepG2 cell line was grown in Dulbecco's Modified Eagle's Medium, supplemented with $10 \%$ of heat-inactivated Fetal Bovine Serum, 4,500 mg/L glucose, $110 \mathrm{mg} / \mathrm{L}$ sodium/pyruvate and L-glutamine, $100 \mathrm{IU} / \mathrm{mL}$ penicillin and $100 \mu \mathrm{g} / \mathrm{mL}$ streptomycin. All cell lines were passaged when reached $80 \%$ confluence and grown at standard condition (incubation at $37^{\circ} \mathrm{C}$ in a $5 \% \mathrm{CO}_{2}$ atmosphere). For the experiment, each cell line was plated in a 48 -well plate at a concentration of $2 \times 10^{5}$ cells/well, with $90 \%$ medium and $10 \%$ EDTA-plasma from septic patients or controls. Each incubation was performed for 24 hours in triplicate.

\section{Apoptosis Evaluation by Flow Cytometry}

Cell viability, apoptosis and necrosis were assessed using the Annexin V-FITC kit (Beckman Counter, Brea, CA, USA), according to the manufacturer's instructions. Analysis was performed using Navios flow cytometer (Beckman Counter), collecting a total of 100,000 events. Untreated cells were used as negative control.

\section{Caspase-3, -8, -9 and Cytochrome-c Evaluation}

Caspase-3,-8,-9 and cytochrome-c concentrations have been analyzed using the Human enzyme-linked immunosorbent assay kit (eBioscience, San Diego, CA, USA). After $24 \mathrm{~h}$ incubation with plasma from septic-patients or controls, cell line lysates were analyzed with VICTOR X4 multilabel Plate Reader (PerkinElmer, Life Sciences, Waltham, MA, USA), according to manufacturer instructions. All experiments have been performed in triplicate.

\section{Statistical Analysis}

GraphPad Prism 7 software (La Jolla, CA, USA) was used to calculate Spearman correlations and non-parametric Mann-Whitney tests to compare groups. Two-tailed 95\% CIs were used to determine significance and significant differences are reported as $p$ values with $p^{*}<0.05,{ }^{* *} p<0.01,{ }^{* * *} p<0.001$ and ${ }^{* * * *} p<0.0001$. 
Table 1. Demographic and clinical data for the 26 septic patients

\begin{tabular}{|c|c|}
\hline Parameters & Values \\
\hline Age, years, mean $\pm S D$ & $62.5 \pm 17.7$ \\
\hline Gender, \% & 68 \\
\hline Mortality, \% & 67 \\
\hline CRRT, \% & 36 \\
\hline Cause of infection (in $68 \%$ cases) & $\begin{array}{l}31 \% \text { Fungi, } \\
54 \% \text { Gram-, } \\
15 \% \text { Gram+ }\end{array}$ \\
\hline Serum creatinine, mg/dL, median (IQR) & $1.9(0.9-3.8)$ \\
\hline Temperature, ${ }^{\circ} \mathrm{C}$, median (IQR) & $37.1(35.5-38.9)$ \\
\hline $\mathrm{pH}$, median (IQR) & $7.4(7.4-7.5)$ \\
\hline Urinary volume, $\mathrm{mL} / 24 \mathrm{~h}$, median (IQR) & $1,360(382-3090)$ \\
\hline Urea, mg/dL, median (IQR) & $105(58-199)$ \\
\hline $\mathrm{Na}^{+}, \mathrm{mmol} / \mathrm{L}$, median (IQR) & $140(137-146)$ \\
\hline $\mathrm{K}^{+}, \mathrm{mmol} / \mathrm{L}, \operatorname{median}(\mathrm{IQR})$ & $3.9(3.6-4.4)$ \\
\hline WBC, $\times 10^{3}$ cells $/ \mu \mathrm{L}$, median (IQR) & $10.8(6.5-15.0)$ \\
\hline Platelets, $\times 10^{3}$ cells $/ \mu \mathrm{L}$, median (IQR) & $94(57-139)$ \\
\hline Procalcitonin, ng/mL, median (IQR) & $10.9(0.7-25.0)$ \\
\hline
\end{tabular}

\section{Results}

\section{Characteristics of Septic Patients'}

Table 1 shows demographic and clinical data for the 26 septic patients enrolled in this study. The average age was $62.5 \pm 17.7$ years, $68 \%$ were males, $36 \%$ received continuous renal replacement therapy and $33 \%$ had a good prognosis when discharged from the hospital. Culture test was performed for each patient and resulted positive in $68 \%$ of cases, while for the remaining 32\%, the cause of infection was unknown. The average age of the healthy control group $(n=20)$ was $52 \pm 7.7$ years and $44 \%$ were males.

\section{Effect of Septic-Plasma on RTCs, U937 and HepG2}

Viability

To analyze the effects of inflammatory mediators on cell death, we evaluated cell viability in RTCs, U937 and HepG2 incubated with plasma from septic patients, compared to control cells incubated with healthy donors' plasma. For all cell lines, cell viability significantly decreased in the test compared to the control group; specifically, the percentage of life cells was 70.45\% (IQR 56.5-73.4) and 96.8\% (IQR 94.8-97.5) in test versus control-RTCs, 76.90\% (IQR 61.5-88.9) and 96.2\% (IQR 95.1-97.5) in test versus control-U937, 73.30\% (IQR 46.7-82.9) and 85.2\% (IQR 79.3-92.6) in test versus control-HepG2 cells (Fig. 1a). Similarly, apoptosis levels significantly increased in the RTCs and U937 test group, reaching the 25.1\% (IQR 15.7-35.6) in RTCs and 12.2\% (IQR 9.0-26.4) in U937, compared to the physiologic apoptotic level of both control groups (1.4\%, IQR 1.2-1.9 and 1.9\%, IQR 1.7-2.3 for RTCs and U937, respectively). On the contrary, apoptosis in HepG2 cells did not change (5.1\%, IQR 2.5-8.2 in test versus control 4.2\%, IQR 2.5-4.7). Interestingly, HepG2 test group showed higher necrosis levels (17.8\%, IQR 6.150.4) compared to its control group (12.6\%, IQR $12.1-$ 13.9; Fig. 1c). Furthermore, differences in necrosis levels were also evident with respect to the RTCs and U937 test groups (4.3\%, IQR 1.3-8.9 and 4.6\%, IQR 2.7-12.5, respectively). Although necrosis slightly increased in RTCs and the U937 test group, this increment was not as relevant as changes found at the apoptotic level.

To corroborate apoptosis finding, we measured the levels of caspase-3 in RTCs and U937 cell lines. Strikingly, comparing the test and control groups, we found a 3.8fold and 4.7-fold increase of caspase- 3 levels in RTCs (Fig. 2a) and U937 (Fig. 2c) respectively. As expected, caspase-3 significantly correlated with apoptosis levels in both RTCs $(r=0.65, p<0.0001$; Fig. $2 b)$ and U937 ( $r=$ $0.74, p<0.0001$; Fig. 2 d) cell lines.

\section{Evaluation of Extrinsic and Intrinsic Pathway Activation}

Next, we aimed to understand if apoptosis in RTCs and U936 was triggered by the activation of the intrinsic or extrinsic pathway. Thus, we analyzed the levels of caspase-8, caspase- 9 and cytochrome-c. In both cell lines, caspase- 9 and cytochrome-c levels significantly increased in the test-group, while caspase- 8 levels did not change (Fig. 3a, d). This result suggests the intrinsic pathway activation in these cell lines. This assumption was strengthened by the strong correlation of cytochrome-c and caspase-9 found in both RTCs $(r=0.73, p<0.0001$; Fig. 3b) and U937 cells $(r=0.69, p<0.0001$; Fig. 3e), while no correlation was found between apoptosis and caspase- 8 levels (data not shown; $p=0.14$ for RTCs; $p=0.07$ for U937). In addition, caspase- 9 also positively correlated with caspase-3 levels in both RTCs $(r=0.69, p<0.0001$; Fig. 3c) and U937 cells ( $r=0.63, p<0.0001$; Fig. 3f). All these data support the idea that in septic conditions, tubular epithelial cells and monocytes encounter a mitochondria-mediated programmed cell death.

\section{Discussion}

Sepsis is a systemic inflammatory response to infection, often complicated by multiple organs injury and dysfunction. Several works have suggested that inflam- 


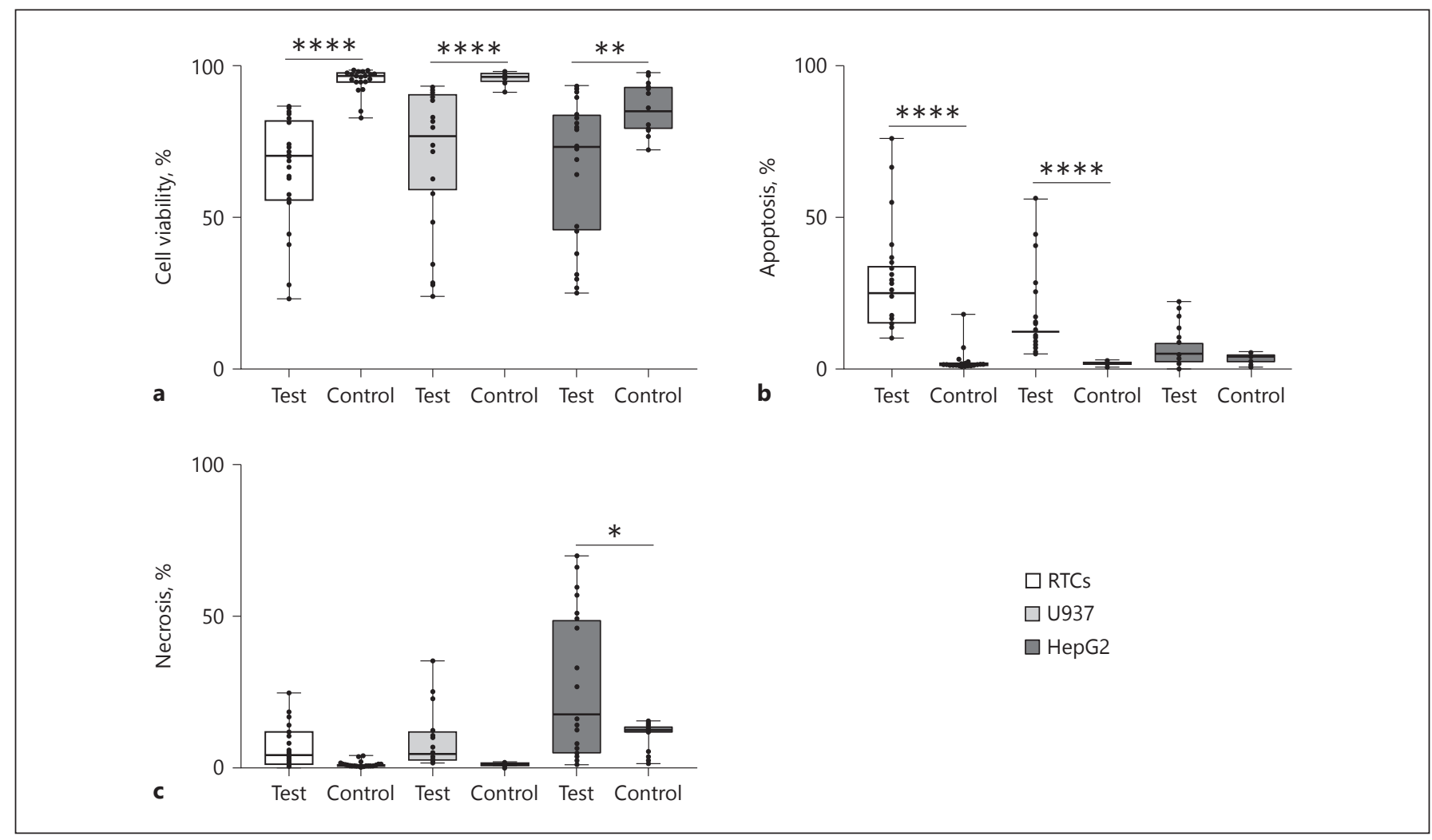

Fig. 1. Direct effects of $24 \mathrm{~h}$-incubation with septic patient's plasma in 3 difference cell lines. Graphs show comparison between the test and the control group of RTCs (white), U937 (square pattern) and HepG2 (line pattern) cell lines for (a) cell viability (b) apoptosis (c) necrosis. Results are shown as mean percentage/100,000 events analyzed. Significant differences are indicated (Mann-Whitney test, $p$ values: $\left.{ }^{*}<0.05,{ }^{* *}<0.01,{ }^{* * *}<0.001,{ }^{* * * *}<0.0001\right)$. matory mediators (such as cytokines and interleukins) play an important role in inducing organ-injury, through direct promotion of apoptosis $[9,10,12,13]$. In this study, we aimed to better characterize the direct effects of septic patients' humoral mediators on cell viability.

Our in vitro data showed an immediate cytotoxic effect after 24-h incubation with septic-plasma, resulting in a decrease of cell viability of all 3 cell lines tested (Fig. 1a). Interestingly, while for RTCs and U937 cells apoptosis increased (Fig. 1b), necrosis appeared to enhance cell death in the HepG2 line (Fig. 1c). Increased apoptosis was confirmed by higher caspase-3 levels found in RTCs and the U937 test group (Fig. 2). Therefore, the effect of humoral mediators on RTCs and monocytes is different compared to hepatocytes response.

The fact that apoptosis was not perturbed in HepG2 suggests this cell line might be resistant to cytotoxic humoral agents. Nonetheless, resistance of healthy hepatocytes to TNF-toxicity has also been reported [15] and several articles have underlined the importance of macro- phages, monocytes and neutrophils in arising hepatotoxicity $[16,17]$, supporting the idea that HepG2 might require interaction and crosstalk with other cells to result in a more realistic response to inflammation. To assess this point, additional experiments using co-cultures of HepG2 (i.e., with monocytes. macrophages etc.) are necessary to improve this model to study sepsis-induced cytotoxicity in hepatocytes.

Our results indicate the activation of the intrinsic apoptotic pathway in RTCs and U937, as cytochrome-c and caspase- 9 levels significantly increased, while caspase-8 did not change after incubation with septic-plasma (Fig. 3a, d). In addition, the positive correlation between caspase- 9 and both caspase- 3 and cytochrome-c, was consistent with the mitochondrial pathway of apoptosis (Fig. 3b, c, e, f). Despite, these findings suggest RTCs and U937 cells die due to environmental stress stimuli (i.e., reactive oxygen species and bacterial toxin) and not as consequence of a direct response to inflammatory mediators (i.e., cytokines, TNF- $\alpha$, INF- $\gamma$ ), we cannot exclude 


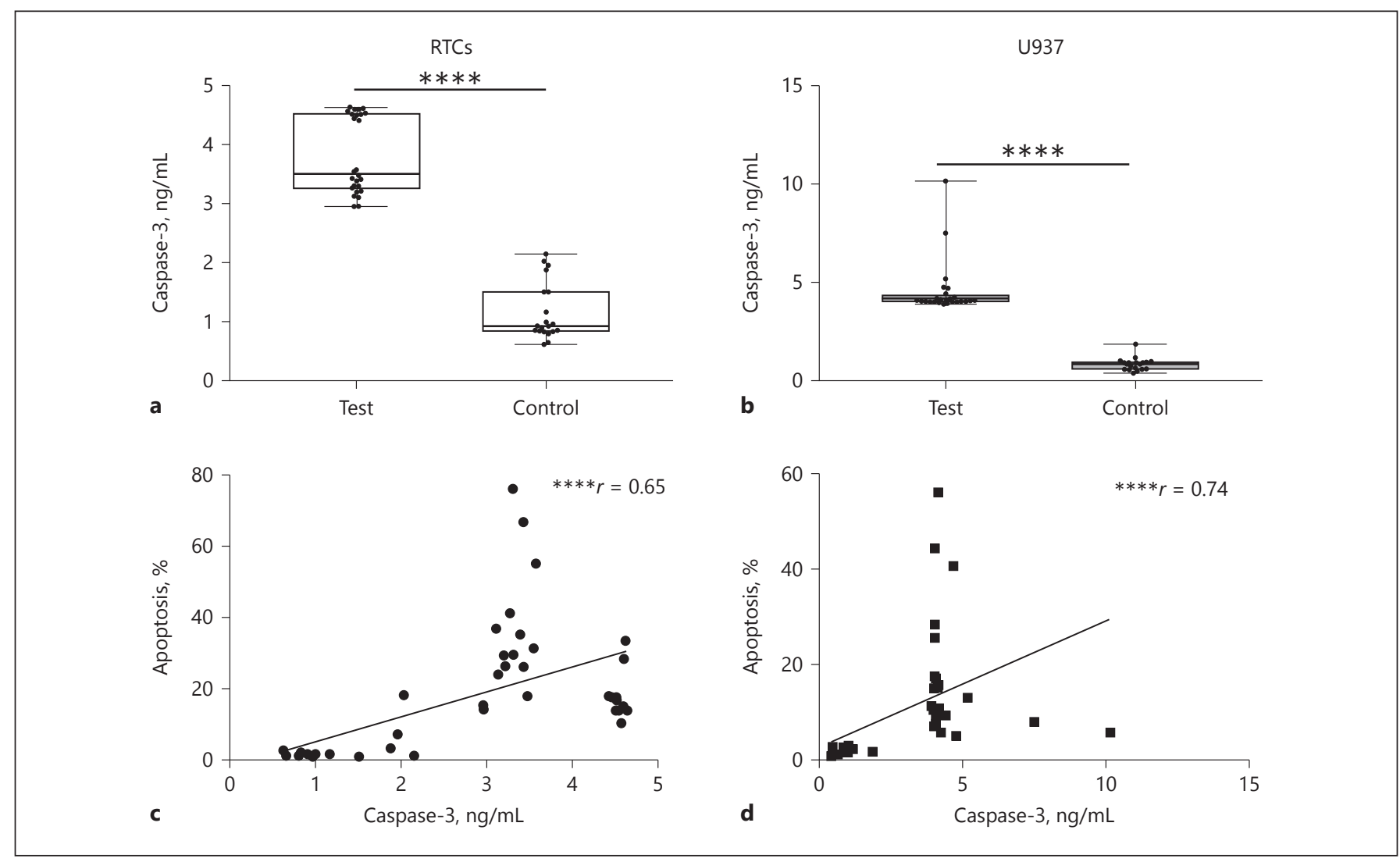

Fig. 2. Caspase-3 levels confirm increase of apoptosis in RTCs and U937 cell lines. Graphs showing increased levels of caspase- 3 in the test group of (a) RTCs and (c) U937 cell lines. Significant differences are shown in Fig.1. Spearman correlation between caspase-3

levels and apoptosis for (b) RTCs ( $p$ value $<0.0001, r=0.65, r^{2}=$ 0.32 ) and (d) U937 cells ( $p$ value ${ }^{* * * *}<0.0001, r=0.74, r^{2}=0.20$ ). The solid line represents linear regression.

that both intrinsic and extrinsic pathways are involved in mediating apoptosis. In fact, the 2 death pathways could activate each other, as activated caspase- 3 has been reported to activate both caspase-8 [18] and caspase- 9 in a retrograde manner [19]. Therefore, quantification of inflammatory mediators of septic patients, such as cytokines and interleukins, may give additional insights into apoptosis induced by sepsis.

\section{Conclusion}

Importantly, our results that septic-conditions induce apoptosis occurred in two thirds of the cell lines tested are in agreement with previous findings; in fact, extensive apoptosis of lymphocytes and gastrointestinal epithelial cells have been described in autopsies of patients with sepsis [20] and animal model studies [21-26], reinforcing the idea that programmed cell death plays a key role in the pathophysiology of sepsis. Moreover, our data are corroborated by results from other papers that studied cell lines incubated with patients' plasma [10, 12, 13,27]. Certainly, this work has the inevitable limitations associated to the in vitro approach and the use of single immortalized human cell lines, which can only partially reproduce the complexity of a phenomenon such as sepsis-induced organ dysfunction involving the cross-talk of multiple lineages. Another limitation is that the pathogen causing sepsis was not the same for all patients enrolled in this study, resulting in an increased heterogeneity within the septic group. Overall, this study reinforces the importance of apoptosis in the pathophysiology of sepsis, underlining the need to investigate anti-apoptotic treatments as future strategy to prevent or ameliorate organ tissue damages and negative side effects associated with sepsis. 


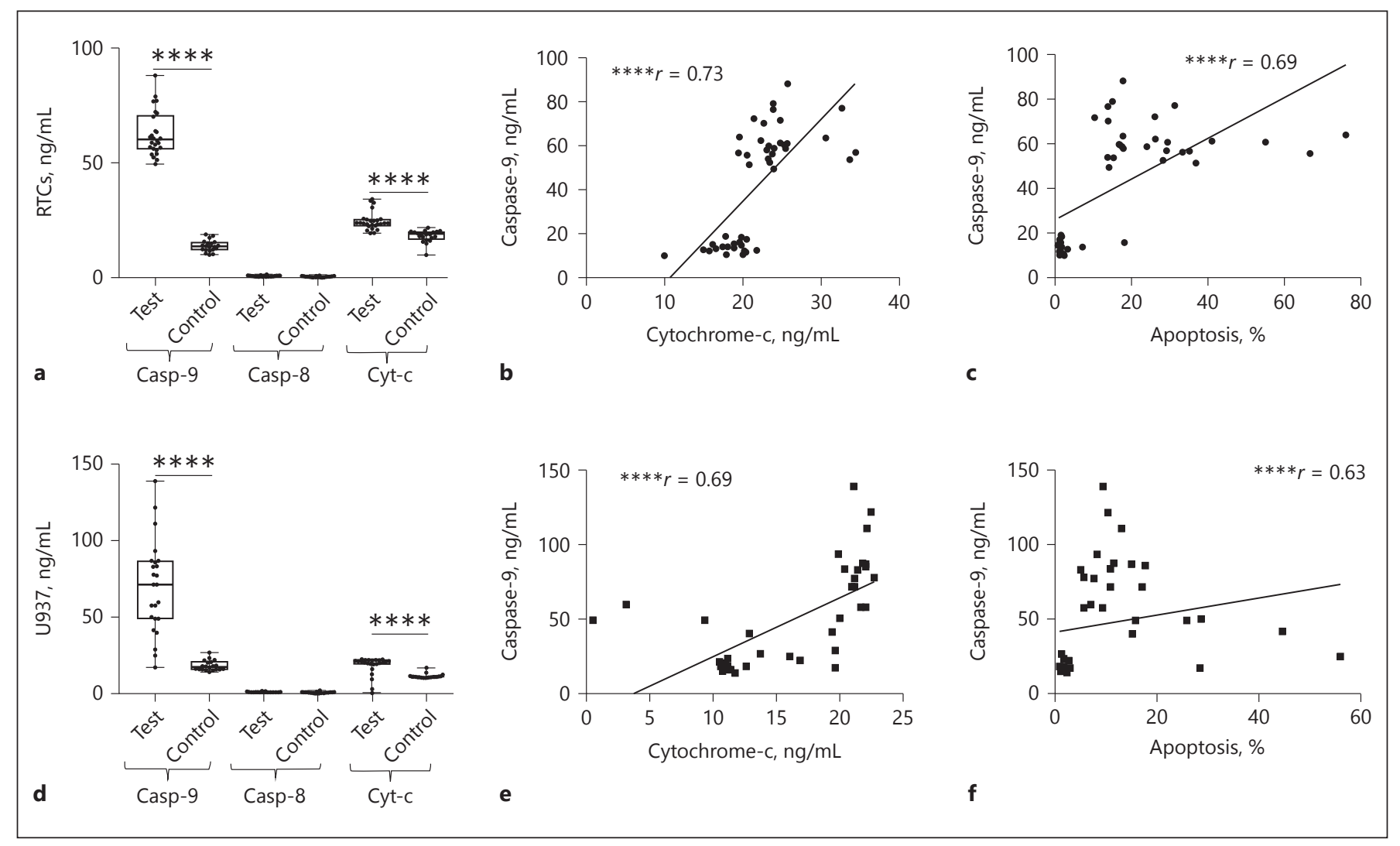

Fig. 3. Sepsis induces the activation of the intrinsic apoptotic pathway in RTCs and U937 cell lines. Comparison of caspase-9, caspase- 8 and cytochrome-c levels between test and control group of (a) RTCs and (d) U937 cells. For RTCs, spearman correlations of

\section{Acknowledgements}

We express our gratefulness to the medical, nursing and secretarial staff from the Intensive Care Unit and the Nephrology Department, St. Bortolo Hospital, Vicenza. We thank Associazione Amici del Rene Vicenza (A.A.R.VI) ONLUS for the financial support.

\section{Disclosure Statement}

The authors declare that they have no competing interests to disclose.

\section{Funding Sources}

This work was supported by Associazione Amici del Rene Vicenza (A.A.R.VI) ONLUS. caspase-9 with cytochrome-c (b) and apoptosis levels (c) are shown. The same data is shown for U937 cells in panel $(\mathbf{e}, \mathbf{f})$, respectively. Solid line represents linear regression. $p$-values: $* * * *<0.0001$.

\section{Authors Contribution}

G.M.V. conceived and designed the study, performed statistical analysis, interpretation and drafting of the manuscript; C.B. performed statistical analysis and prepared the manuscript; C.P. and S.P. and performed the experiments and acquired data; A.B. and M.C. assisted with experiments and data analysis, N.F. and M.Z. and A.B. assisted with study design, enrolled patients, collected data and drafted the manuscript; C.R. provided intellectual content of critical importance to this work, conceived of the study and final approval of the draft. All authors drafted and reviewed the manuscript and also approved of the final manuscript.

\section{Ethics Approval and Consent to Participate}

This study was approved by the Ethics Committee of San Bortolo Hospital in Vicenza and the procedures were in accordance with the Helsinki Declaration. All the patients or their relatives were informed about the experimental protocol and the objectives of the study before providing informed consent and blood samples. 


\section{Consent for Publication}

This manuscript has not been published and is not under consideration elsewhere; the results presented in this paper have not been published previously, except in abstract form. All persons listed have contributed sufficiently to the project to be included as authors, and all those who are qualified to be authors are listed in the author byline. Consent for use of de-identified images contained in this article was given by the individuals involved.

\section{Availability of Data Materials}

The datasets generated and analyzed during this study are available on reasonable request.

\section{References}

1 Singer M, Deutschman CS, Seymour CW, Shankar-Hari M, Annane D, Bauer M, Bellomo R, Bernard GR, Chiche JD, Coopersmith CM, Hotchkiss RS, Levy MM, Marshall JC, Martin GS, Opal SM, Rubenfeld GD, van der Poll T, Vincent JL, Angus DC: The third international consensus definitions for sepsis and septic shock (sepsis-3). JAMA 2016;315: 801-810.

2 https://www.cdc.gov/sepsis/datareports/index.html.

3 Suarez De La Rica A, Gilsanz F, Maseda E: Epidemiologic trends of sepsis in western countries. Ann Transl Med 2016;4:325.

4 Gaieski DF, Edwards JM, Kallan MJ, Carr BG: Benchmarking the incidence and mortality of severe sepsis in the United States. Crit Care Med 2013;41:1167-1174.

5 Cuthbertson BH, Elders A, Hall S, Taylor J, MacLennan G, Mackirdy F, Mackenzie SJ; Scottish Critical Care Trials G, Scottish Intensive Care Society Audit G: Mortality and quality of life in the five years after severe sepsis. Crit Care 2013;17:R70.

6 Rhodes A, Evans LE, Alhazzani W, Levy MM, Antonelli M, Ferrer R, Kumar A, Sevransky JE, Sprung CL, Nunnally ME, Rochwerg B, Rubenfeld GD, Angus DC, Annane D, Beale RJ, Bellinghan GJ, Bernard GR, Chiche JD, Coopersmith C, De Backer DP, French CJ, Fujishima S, Gerlach H, Hidalgo JL, Hollenberg SM, Jones AE, Karnad DR, Kleinpell RM, Koh Y, Lisboa TC, Machado FR, Marini JJ, Marshall JC, Mazuski JE, McIntyre LA, McLean AS, Mehta S, Moreno RP, Myburgh J, Navalesi P, Nishida O, Osborn TM, Perner A, Plunkett CM, Ranieri M, Schorr CA, Seckel MA, Seymour CW, Shieh L, Shukri KA, Simpson SQ, Singer M, Thompson BT, Townsend SR, Van der Poll T, Vincent JL, Wiersinga WJ, Zimmerman JL, Dellinger RP: Surviving Sepsis Campaign: International Guidelines for Management of Sepsis and Septic Shock: 2016. Intensive Care Med 2017; 43:304-377.

7 Yan J, Li S, Li S: The role of the liver in sepsis. Int Rev Immunol 2014;33:498-510.

8 Tetta C, Mariano F, Buades J, Ronco C, Wratten ML, Camussi G: Relevance of platelet-activating factor in inflammation and sepsis: mechanisms and kinetics of removal in extra- corporeal treatments. Am J Kidney Dis 1997; 30(5 suppl 4):S57-S65.

9 Cunningham PN, Dyanov HM, Park P, Wang J, Newell KA, Quigg RJ: Acute renal failure in endotoxemia is caused by TNF acting directly on TNF receptor-1 in kidney. J Immunol 2002; $168: 5817-5823$

10 Mariano F, Cantaluppi V, Stella M, Romanazzi GM, Assenzio B, Cairo M, Biancone L, Triolo G, Ranieri VM, Camussi G: Circulating plasma factors induce tubular and glomerular alterations in septic burns patients. Crit Care 2008; 12:R42

11 Simmons EM, Himmelfarb J, Sezer MT, Chertow GM, Mehta RL, Paganini EP, Soroko S, Freedman S, Becker K, Spratt D, Shyr Y, Ikizler TA, Group PS: Plasma cytokine levels predict mortality in patients with acute renal failure. Kidney Int 2004;65: 1357-1365.

12 Virzi GM, Clementi A, Brocca A, de Cal M, Marcante S, Ronco C: Cardiorenal syndrome type 5 in sepsis: role of endotoxin in cell death pathways and inflammation. Kidney Blood Press Res 2016;41:10081015.

13 Brocca A, Virzi GM, Pasqualin C, Pastori S, Marcante S, de Cal M, Ronco C: Cardiorenal syndrome type 5 : in vitro cytotoxicity effects on renal tubular cells and inflammatory profile. Anal Cell Pathol (Amst) 2015;2015: 469461.

14 Xiao Z, Wilson C, Robertson HL, Roberts DJ, Ball CG, Jenne CN, Kirkpatrick AW: Inflammatory mediators in intra-abdominal sepsis or injury - a scoping review. Crit Care 2015; 19:373.

15 Seijo Y, Hirata I, Onoda H: [Staining effects of various dyes on Treponema pallidum (a pathogenic Nichols strain)]. Nihon Saikingaku Zasshi 1978;33:547-550.

16 Roberts RA, Ganey PE, Ju C, Kamendulis LM, Rusyn I, Klaunig JE: Role of the Kupffer cell in mediating hepatic toxicity and carcinogenesis. Toxicol Sci 2007;96:2-15.

17 Granitzny A, Knebel J, Muller M, Braun A, Steinberg P, Dasenbrock C, Hansen T: Evaluation of a human in vitro hepatocyte-NPC coculture model for the prediction of idiosyncratic drug-induced liver injury: a pilot study. Toxicol Rep 2017;4:89-103.
18 Creagh EM, Martin SJ: Caspases: cellular demolition experts. Biochem Soc Trans 2001;29: 696-702.

19 Hotchkiss RS, Nicholson DW: Apoptosis and caspases regulate death and inflammation in sepsis. Nat Rev Immunol 2006;6:813-822.

20 Hotchkiss RS, Swanson PE, Freeman BD, Tinsley KW, Cobb JP, Matuschak GM, Buchman TG, Karl IE: Apoptotic cell death in patients with sepsis, shock, and multiple organ dysfunction. Crit Care Med 1999;27:1230-1251.

21 Hiramatsu M, Hotchkiss RS, Karl IE, Buchman TG: Cecal ligation and puncture (CLP) induces apoptosis in thymus, spleen, lung, and gut by an endotoxin and TNF-independent pathway. Shock 1997;7:247-253.

22 Hotchkiss RS, Swanson PE, Cobb JP, Jacobson A, Buchman TG, Karl IE: Apoptosis in lymphoid and parenchymal cells during sepsis: findings in normal and T- and B-cell-deficient mice. Crit Care Med 1997;25:12981307.

23 Chung CS, Xu YX, Wang W, Chaudry IH, Ayala A: Is Fas ligand or endotoxin responsible for mucosal lymphocyte apoptosis in sepsis? Arch Surg 1998;133:12131220.

24 Oberholzer C, Oberholzer A, Bahjat FR, Minter RM, Tannahill CL, Abouhamze A, LaFace D, Hutchins B, Clare-Salzler MJ, Moldawer LL: Targeted adenovirus-induced expression of IL-10 decreases thymic apoptosis and improves survival in murine sepsis. Proc Natl Acad Sci U S A 2001;98:1150311508.

25 Oberholzer C, Oberholzer A, Clare-Salzler M, Moldawer LL: Apoptosis in sepsis: a new target for therapeutic exploration. FASEB J 2001; 15:879-892.

26 Coopersmith CM, Stromberg PE, Dunne WM, Davis CG, Amiot DM 2nd, Buchman TG, Karl IE, Hotchkiss RS: Inhibition of intestinal epithelial apoptosis and survival in a murine model of pneumonia-induced sepsis. JAMA 2002;287:1716-1721.

27 Cantaluppi V, Weber V, Lauritano C, Figliolini F, Beltramo S, Biancone L, De Cal M, Cruz D, Ronco C, Segoloni GP, Tetta C, Camussi G: Protective effect of resin adsorption on septic plasma-induced tubular injury. Crit Care 2010;14:R4 